\title{
SYNCHRONIZATION OF OESTRUS AND FERTILITY FOLLOWING ARTIFICIAL INSEMINATION IN HEIFERS GIVEN PROSTAGLANDIN $F_{2 \alpha}$
}

\author{
J. F. ROCHE \\ The Agricultural Institute, Grange, Dunsany, Co. Meath, Ireland
}

(Received 24th September 1973)

The oestrous cycle of the cow is controlled mainly by the secretion of progesterone from the CL. Effective synchronization of oestrus requires control of the functional life span of the CL. Injections of oxytocin from Days 2 to 6 of the oestrous cycle (Armstrong \& Hansel, 1959), injections of oestrogen (Wiltbank, Ingalls \& Rowden, 1961), the presence of foreign bodies in the uterus (Hansel \& Wagner, 1960), irrigation of the uterus with iodine solutions (Nakahara, Domeki \& Yamauchi, 1971) or administration of LH antibodies (Snook, Brunner, Saatman \& Hansel, 1969) all cause premature luteolysis in cattle. Few of these methods of inducing CL regression, however, have been incorporated into synchronizing treatments. Administration of progestagens for the length of an oestrous cycle to suppress oestrus and ovulation, without reducing the functional life span of the CL, has been the most widely used method of synchronization. Following this method, fertility to natural or artificial mating at the controlled heat has been low (Mauléon \& Chupin, 1971 ; Jöchle, 1972).

Prostaglandin $\mathrm{F}_{2 \alpha}\left(\mathrm{PGF}_{2 \alpha}\right)$, given either locally into the uterine horn ipsilateral to the CL (Rowson, Tervit \& Brand, 1972) or systemically (Lauderdale, 1972), is effective in causing luteal regression in the cow. This ability to induce luteal regression and the presence of $\mathrm{PGF}_{2 \alpha}$ in the uterus in increasing concentrations around the time of normal CL regression has led some workers (McCracken, Garlson, Glew, Goding, Baird, Green \& Samuelsson, 1972) to conclude that $\mathrm{PGF}_{2 \alpha}$ is 'the luteolysin' in the ewe. Because of its ability to induce CL regression, an experiment was conducted to determine the fertility to AI in heifers following attempts to induce oestrus with one systemic injection of different dose levels of PGF $2 \alpha$.

Since $\mathrm{PGF}_{2 \alpha}$ is only effective in causing luteal regression between Days 5 and 16 of the oestrous cycle (Rowson et al., 1972), the date of occurrence of oestrus was obtained by running a vasectomized bull, fitted with a chin-ball mating device, with forty-one cycling Hereford cross heifers. On the day of injection of $\mathrm{PGF}_{2 \alpha}$, eight animals which had been in oestrus during the previous 5 days were eliminated from the experiment. The remaining thirty-three heifers, which were between Days 5 and 20 of the oestrous cycle, were allotted at random to three treatments based on the stage of the cycle: (i) untreated controls, (ii) $30 \mathrm{mg}$ and (iii) $20 \mathrm{mg}$ PGF $_{2 \alpha}$ injected intramuscularly. The 
heifers were then individually checked for the occurrence of heat on 4 subsequent days with a vasectomized bull at $08.00,14.00$ and 20.00 hours. After checking at 20.00 hours, a vasectomized bull was run overnight with those heifers which had not yet shown heat. After the 4th day, a vasectomized bull was run continuously with the heifers to detect the onset of oestrus until all the control animals had been artificially inseminated. The same procedure was used to determine the number of inseminated heifers returning to oestrus. All heifers in oestrus were inseminated with frozen semen from the same bull by an inseminator from a commercial AI station. Heifers in oestrus during the night and still standing at 08.00 hours were inseminated between 15.00 and 17.00 hours the same day; heifers in oestrus during the night and not still standing at 08.00 hours were inseminated between 11.00 and 13.00 hours. Heifers coming into oestrus during the day were inseminated the following morning between 11.00 and 13.00 hours.

Table 1. Effect of prostaglandin $F_{2 \alpha}$ injected on different days of the cycle on the oestrous response in heifers

\begin{tabular}{c|c|c}
\hline & \multicolumn{2}{|c}{ Dose of $P G F_{2 \alpha}$} \\
\cline { 2 - 3 } Stage of oestrous cycle & $30 \mathrm{mg}$ & $20 \mathrm{mg}$ \\
\hline Days 7 to 11 & & \\
No. of heifers & 6 & 6 \\
No. in oestrus* & 4 & 5 \\
Days 12 to 16 & & \\
No. of heifers & 3 & 4 \\
No. in oestrus* & 3 & 4 \\
Days17 to 20 \\
No. of heifers \\
No. in oestrus* & 2 & 1 \\
\hline Total & 1 & 1 \\
\hline No. of heifers & 11 & 11 \\
No. in oestrus* & 8 & 10 \\
\hline
\end{tabular}

* Within 4 days of injection.

The heifers were killed 30 to 40 days after the last insemination, the reproductive tracts were recovered and the number of animals with normal embryos was recorded.

The majority of heifers treated with prostaglandin were detected in oestrus within 4 days of injection. Neither the dose of $\mathrm{PGF}_{2 \alpha}$ nor the stage of the cycle on the day of treatment influenced the oestrous response obtained (Table 1). The length of the oestrous cycle was significantly shortened in the heifers treated with $\mathrm{PGF}_{2 \alpha}$ compared to the controls (Table 2) and there was no difference between the two dose levels used.

The fertility level following AI at the synchronized heat in the heifers treated with $\mathrm{PGF}_{2 \alpha}$ did not differ from the fertility level obtained in the untreated controls. Although the number of animals used in this experiment is small, the normal fertility level in the synchronized heifers is in marked contrast to 
the fertility obtained in heifers synchronized either with synthetic progestagens or progesterone where both natural and artificial mating have been used (Mauléon \& Chupin, 1971; Jöchle, 1972; Roche \& Crowley, 1973).

Since a single intramuscular injection of $\mathrm{PGF}_{2 \alpha}$ is highly effective in inducing CL regression and producing synchronized heat in cattle, the use of prostaglandins for synchronizing oestrus in cattle is worthy of large-scale testing to see if the high fertility obtained in this experiment is repeatable. However, since heifers or cows between Days 1 to 5 of the oestrous cycle are not responsive to $\mathrm{PGF}_{2 \alpha}$, it will be necessary to overcome this problem before it can be widely used. One method would be to inject all animals initially, regardless of the stage of cycle, and then to re-treat those heifers not responding 10 days later, at which time they would be responsive to $\mathrm{PGF}_{2 \alpha}$. The dose of $\mathrm{PGF}_{2 \alpha}$ required intramuscularly is high but already there are reports (Tervit, Rowson \& Brand, 1973) on the effective use of more potent synthetic analogues of $\mathrm{PGF}_{2 \alpha}$ for the synchronization of oestrus in cattle.

Table 2. Effect of $\mathrm{PGF}_{2 \alpha}$ on the length of the cycle and fertility in heifers

\begin{tabular}{l|c|c|c}
\hline & \multicolumn{3}{|c}{ Dose of $P G F_{2 x}$} \\
\cline { 2 - 4 } & $30 \mathrm{mg}$ & $20 \mathrm{mg}$ & Controls \\
\hline No. of animals & 11 & 11 & 11 \\
No. in oestrus & 8 & 10 & 11 \\
Interval from injection to oestrus (hr)* & $59 \pm 3 \cdot 3$ & $64 \pm 8 \cdot 9$ & \\
Length of oestrous cycle (days)* & $14 \cdot 7 \pm 1 \cdot 22 \dagger$ & $14 \cdot 8 \pm 1 \cdot 22 \dagger$ & $20 \cdot 8 \pm 0 \cdot 34 \dagger$ \\
No. pregnant and (\%) & $6(75)$ & $7(70)$ & $8(73)$ \\
No. returning to oestrus & 2 & 3 & 3 \\
\hline
\end{tabular}

* Mean + S.E.

$\dagger$ Significantly different from controls $(P<0 \cdot 001)$.

The mechanism of action of prostaglandins in causing luteal regression is not clear at present although it has been postulated that the luteolytic effect is due to its vasoconstrictor properties (Pharriss \& Wyngarden, 1969). Further studies are required to elucidate the mechanism of action, to assess the minimum effective systemic dose, the potency of various analogues, and the possible side effects, before prostaglandins can be routinely used since these compounds are involved in many biochemical processes in the body.

Prostaglandin $\mathbf{F}_{2 \alpha}$ was supplied by Upjohn Co. Mr D. Prendiville rendered excellent technical assistance.

\section{REFERENCES}

Armstrong, D. T. \& Hansel, W. (1959) Alteration of the bovine estrous cycle with oxytocin. F. Dairy Sci. 42, 533.

Hansed, W. \& WagneR, W. C. (1960) Luteal inhibition in the bovine as a result of oxytocin injections, uterine dilation and uterine infusions of seminal and preputial fluids. F. Dairy Sci. 43, 796.

Jöchle, W. (1972) Pharmacological aspects of the control of the cycle in domestic animals. 6 th Int. Congr. Anim. Reprod. \& A.I., Munich, 6-9 June 1972, 1, 97. 
Lauderdale, J. W. (1972) Effects of PGF Pa $_{2 \alpha}$ on pregnancy and estrous cycle of cattle. F. Anim. Sci. $35,246$.

Maulton, P. \& Ghupin, D. (1971) Maitrise des cycles sexuels chez les bovines. Econ. Med. anim. 12, 31.

McGracken, J. A., Carlson, J. C., Glew, M. E., Goding, J. R., Baird, D. T., Green, K. \& Samuelsson, B. (1972) Prostaglandin $F_{2 \alpha}$ identified as a luteolytic hormone in sheep. Nature, New Biology, 238, 129.

Nakahara, T., Domeki, I. \& Yamauchi, M. (1971) Effects of intrauterine injection of iodine solution of the estrous cycle length of the cow. Natn. Inst. Anim. Hlth Q., Tokyo, 11, 211.

Pharriss, B. B. \& Wyngarden, L. J. (1969) The effect of prostaglandin $F_{2 x}$ on the progestagen content of ovaries from pseudopregnant rats. Proc. Soc. exp. Biol. Med. 130, 92.

Roche, J. F. \& CROWLEY, J. P. (1973) The fertility of heifers inseminated at predetermined intervals following treatment with MGA and HCG to control ovulation. 7. Reprod. Fert. 35, 211.

Rowson, L. E. A., TERvit, H. R. \& BRAND, A. (1972) The use of prostaglandins for synchronization of oestrus in cattle. . . Reprod. Fert. 29, 145.

Snook, R. B., Brunner, M. A., SaAtman, R. R. \& Hansel, W. (1969) The effect of antisera to bovine LH in hysterectomized and intact heifers. Biol. Reprod. 1, 49.

Tervit, H. R., Rowson, L. E. A. \& Brand, A. (1973) Synchronization of oestrus in cattle using a prostaglandin $\mathbf{F}_{2 \alpha}$ analogue (ICI 79939). $\mathcal{F}$. Reprod. Fert. 34, 179.

Wiltbank, J. N., Ingalls, J. E. \& Rowden, W. W. (1961) Effects of various forms and levels of estrogens alone or in combinations with gonadotrophins on the estrous cycle of beef heifers. 7. Anim. Sci. 20, 341 . 